\title{
Evaluation of strategies for improving the transgene expression in an oleaginous microalga Scenedesmus acutus
}

Anongpat Suttangkakul ${ }^{1,2}$, Anchalee Sirikhachornkit ${ }^{1,2}$, Piyada Juntawong ${ }^{1,2}$, Wilasinee Puangtame ${ }^{1}$, Thitikorn Chomtong ${ }^{1}$, Suchada Srifa ${ }^{1}$, Sukhita Sathitnaitham', Wasawat Dumrongthawatchai ${ }^{1}$, Kanidtha Jariyachawalid ${ }^{3}$ and Supachai Vuttipongchaikij ${ }^{1,2^{*}}$ (i)

\begin{abstract}
Background: Genetic transformation of microalgae has been hampered by inefficient transgene expression, limiting the progress of microalgal biotechnology. Many vector tools and strategies have been developed in recent years to improve transgene expression in the model microalga Chlamydomonas, but these were hardly applied to other microalgae. In this work, naturally-isolated oleaginous microalgae were accessed for genetic transformation, and various expression systems were evaluated in a selected microalga to circumvent inefficient transgene expression.

Results: Initially, a strain of Scenedesmus acutus was selected from the oleaginous microalgal collection based on its highest transformation rate and transgene stability. This strain, which had very low or no GFP reporter expression, was first tested to improve transgene expression by using intron-containing constructs and the transcript fusion using ble::E2A. The intron-containing constructs yielded $2.5-7.5 \%$ of transformants with $2-4$-fold fluorescence signals, while the majority of the transformants of the transcript fusion had the fluorescence signals up to 10-fold. Subsequently, three UV-induced $S$. acutus mutants were isolated with moderate increases in the level and frequency of transgene expression (2-3-fold and 10-12\%, respectively). Finally, a transcript fusion system was developed using psy white mutants with an expression vector containing PSY::E2A for complementation and light selection. Transformants with green colonies were selected under light exposure, and the transgene expression was detected at protein levels. Although the improvement using PSY::E2A was only minor (1-2-fold increase and 7\% of transformants), this system provides an alternative selectable marker that is compatible with large-scale culture.
\end{abstract}

Conclusions: Here, the overall improvement of transgene expression using the Chlamydomonas tools was moderate. The most effective tool so far is the transcript fusion using ble::E2A system. This work demonstrates that, so far, genetic engineering of non-model microalgae is still a challenging task. Further development of tools and strategies for transgene expression in microalgae are critically needed.

Keywords: Agrobacterium-mediated transformation, Biofuel, Fluorescence reporter, Introns, Lipid, Microalgae, Mutagenesis, Transcript-fusion

\footnotetext{
* Correspondence: fsciscv@ku.ac.th

${ }^{1}$ Special Research Unit in Microalgal Molecular Genetics and Functional Genomics (MMGFG), Department of Genetics, Faculty of Science, Kasetsart University, 50 Ngam Wong Wan road, Chatuchak, Bangkok 10900, Thailand ${ }^{2}$ Center of Advanced studies for Tropical Natural Resources, Kasetsart University, 50 Ngam Wong Wan road, Chatuchak, Bangkok 10900, Thailand Full list of author information is available at the end of the article
}

(c) The Author(s). 2019 Open Access This article is distributed under the terms of the Creative Commons Attribution 4.0 International License (http://creativecommons.org/licenses/by/4.0/), which permits unrestricted use, distribution, and reproduction in any medium, provided you give appropriate credit to the original author(s) and the source, provide a link to the Creative Commons license, and indicate if changes were made. The Creative Commons Public Domain Dedication waiver (http://creativecommons.org/publicdomain/zero/1.0/) applies to the data made available in this article, unless otherwise stated. 


\section{Background}

Oleaginous microalgae emerged as a promising renewable feedstock for biofuel production [1-3]. These microalgae can be cultivated using wastewater, seawater or simple medium and, under certain conditions such as nutrient deprivation or stresses, they can accumulate high lipid contents [4]. For decades, microalgae have been isolated and screened from natural sources for properties beneficial to biofuel production including rapid cell growth, high lipid yields, tolerance to stresses, ease of harvest and ability to secrete lipid [5]. To date, however, these microalgae are unable to produce biofuels at competitive costs compared to those of fossil fuels. Genetic improvement is a major step for making algal biofuels economically feasible $[6,7]$.

Genetic transformation has not been widely used in microalgae, partly because of difficulties in nuclear gene transformation, as reported in the model microalga Chlamydomonas reinhardtii and other species for low transformation efficiencies [8], inefficient transgene expression [9], transgene cleavages [9, 10], transgene instability [11] and highly control transcriptional silencing $[12,13]$. Genome editing was also proved to be very difficult as the homology-directed repair (HDR) is extremely inefficient $[14,15]$ and CRISPR/Cas9 system was shown to be toxic for the algal cell [16]. The only exception so far is a marine microalga Nannochloropsis, which was reported for an efficient nuclear transformation and its feasibility for genome editing by either HDR [17] and CRISPR/Cas9 [18]. Initially, many attempts were made for improving transgene expression in Chlamydomonas by codon optimization [19] and screening large numbers of transformants to minimize transgene positional effects [20], but little improvement was achieved. Recent developments have demonstrated marked improvements by a number of approaches including mutant isolations for reduced transcriptional silencing [21] and the incorporation of introns in the expression constructs [22] and transcript fusion system [23]. However, most of these tools were developed for Chlamydomonas, and only a few have been applied in other microalgae [24].

Various oleaginous microalgae have been tested for genetic transformation, and, indeed, they suffer from inefficient transgene expression as Chlamydomonas had in the past $[25,26]$. Notably, most of the work reported so far relied on the gene or enzymatic activity to represent the transgene expression, without confirmation at protein levels [24, 27-29]. This shortcoming is problematic as reliable detection at protein levels is the key indicator for establishing stable transgene expression, before evaluating the effects of transgenes such as phenotypes or compound production. Along the line of improvements in Chlamydomonas, many developed tools and strategies are now available, and it would be proven fruitful if these could be used for improving other oleaginous microalgae.

Here, ten oleaginous microalgae isolated from natural sources in Thailand were tested for genetic transformation. Initially, some of these microalgae were tested by electro-transformation, but very few or no transformant was obtained. In contrast, Agrobacterium-mediated transformation yielded much more transformants and was used to access the transformation efficiency of the ten microalgae. A strain of $S$. acutus, which has rapid growth and high lipid accumulation, was selected based on its high transformation rate and transgene stability. As expected, this strain has a low capability for transgene expression as indicated by very low levels of GFP reporter. This strain was then used for evaluating various expression tools, which were previously developed in Chlamydomonas, whether they could mitigate the low transgene expression problem. These included the use of constructs containing introns, constructs with transcript fusion and mutant isolation for reduced transcriptional gene silencing. Furthermore, a transgene expression system using novel selectable marker was developed by generating psy white mutants and complementation using PSY gene and light as the mean of selection. Transgene expression was analyzed for both expression levels and the frequency of expressors among the transformants.

\section{Results}

Agrobacterium-mediated transformation of wild-isolated oleaginous microalgal strains

Ten wild-isolated freshwater unicellular microalgae with high lipid accumulations were tested for Agrobacterium-mediated transformation using a method based on Kumar et al. [30]. Before transformation, axenic cultures of the ten strains were verified for hygromycin B sensitivity to estimate the selective concentrations (Additional file 1). After transformation using Agrobacterium harboring pCXSN-GFP, hygromycin B resistant colonies were obtained from six out of ten strains with transformation rates approximately $10-200 \mathrm{CFU}$ per $10^{6}$ cells (Table 1 , see also Additional file 2 for an example of selection plates). Some background colonies conferring spontaneous resistant to hygromycin B were observed from TISTR8511, 8555, 8519, 8540 and 8447, accounting for 5$9 \%$ of total colonies counted in transformation plates. Two S. acutus strains with the highest transformation rates, TISTR8540 and 8447, were tested for assessing the transgene stability. After 10-12 rounds of subcultures on the non-selective medium before transferring onto the hygromycin B selective medium, the growth of the TISTR8447 transformants was more consistent on the selective medium than those of TISTR8540 transformants 
Table 1 Transformation rates of ten microalgal strains by Agrobacterium-mediated transformation

\begin{tabular}{|c|c|c|c|c|c|}
\hline Species & $\begin{array}{l}\text { Algal } \\
\text { media }\end{array}$ & $\begin{array}{l}\text { Concentration of } \\
\text { hygromycin B } \\
\left(\mu \mathrm{g} \mathrm{ml}^{-1}\right)\end{array}$ & $\begin{array}{l}\text { Selection period } \\
\text { (days) }\end{array}$ & $\begin{array}{l}\text { Transformation rate } \\
\text { (CFU per } 10^{6} \text { cells) }\end{array}$ & $\begin{array}{l}\text { Background control } \\
\text { (CFU per } 10^{6} \text { cells) }\end{array}$ \\
\hline Coelastrum sp. (TISTR 8511) & TAP & 10 & 15 & $0(n=44)$ & 0 \\
\hline S. acutus (TISTR 8555) & TAP & 30 & 15 & $20 \pm 5.5(n=12)$ & $1.5 \pm 1.3$ \\
\hline S. acutus (TISTR 8540) & TAP & 50 & 10 & $72 \pm 41(n=8)$ & $3.7 \pm 3.5$ \\
\hline S. acuminatus (TISTR 8519) & TAP & 50 & 10 & $31 \pm 23(n=11)$ & $2.7 \pm 2.5$ \\
\hline S. acutus (TISTR 8447) & TAP & 30 & 15 & $217.5 \pm 75(n=12)$ & $19.5 \pm 6.8$ \\
\hline C. humicola (TISTR 8434) & TAP & 20 & 15 & $10.8 \pm 32(n=4)$ & 0 \\
\hline M. braunii (TISTR 8429) & BG-11 & 10 & 15 & $0(n=8)$ & 0 \\
\hline A. falcatus (TISTR 8557) & BG-11 & 10 & 15 & $0(n=12)$ & 0 \\
\hline T. cumbricus (TISTR 8480) & TAP & 50 & 18 & $9 \pm 8.8(n=5)$ & 0 \\
\hline A. densus (TISTR 8505) & $B G-11$ & 10 & 15 & $0(n=8)$ & 0 \\
\hline
\end{tabular}

(Additional file 3). This result suggests the higher stability of transgenes in TISTR8447. This S. acutus TISTR8447 was used for subsequent studies.

\section{Evaluation of TISTR8447 as a platform for gene expression}

TISTR8447 is a fast-growing strain, reaching its stationary phase within 5 days in TAP medium. It accumulates high lipid contents up to $3 \pm 0.17$ and $10 \pm 1.04 \%$ dry weight in $\mathrm{N}$-supplemented and $\mathrm{N}$-deprived media, respectively, based on total lipid quantification using vanillin staining. The lipid content in this strain is somewhat in moderate levels for lipid production as compared to other potential feedstock microalgae [31]. Nile red staining also showed the abundance of lipid droplets in the cells (Additional file 4). TISTR8447 was further tested for transformation efficiency using four Agrobacterium strains: A41, EHA105, GV3101 and LBA4404. Despite no statistical difference among the Agrobacterium strains $(p>0.05)$, EHA105 and GV3101 appeared to provide the highest transformation rates (Additional file 5). The effect of Acetosyringone was tested, but no significant difference among the tested concentrations $(0,50,100$ and $200 \mu \mathrm{M})$ was observed ( $p>0.05$, data not shown), indicating that Acetosyringone is not required.

Transformed TISTR8447 were analyzed for the presence and expression of the transgene. Among 15 randomly selected potential-transformants subjected to either PCR or RT-PCR analysis, the aphIV gene (hygromycin B resistant gene) and its transcript was detected in 12 and 13 transformants, respectively (Additional file 6). This analysis indicates that most of the hygromycin B resistant colonies contained the transgene. However, after analyzing more than 60 transformants by confocal microscopy, little or no GFP signal was detected above the autofluorescence background (Additional file 6). RT-PCR of the GFP transcript and immunoblot analysis using anti-GFP antibody also failed to detect the presence of the transcript and protein (data not shown). These data demonstrate that TISTR8447 is a potential microalgal strain for biofuel production through its properties for growth, lipid accumulation and its ability to be efficiently transformed by Agrobacterium, but has a very low capacity for transgene expression.

\section{Transgene expression in TISTR8447 using Chlamydomonas introns}

To test the effect of introns in transgene expression, four expression constructs with Chlamydomonas intron-carrying mRuby2, mCerulean3, mVenus and Clover reporters, which were previously shown to improve transgene expression in Chlamydomonas [22], were tested in the TISTR8447 through electro-transformation. Our electro-transformation rate for TISTR8447 was only $4.95 \pm 5.18$ CFU per $5 \times 10^{6}$ cells $(n=20)$, and no background colony was observed when using paromomycin selection. Noting that electro-transformation of S. obliquus was previously reported as $494 \pm 48 \mathrm{CFU}$ per $10^{6}$ cells [25]. Fluorescence microplate analysis showed that most of the transformants had very low fluorescence signal ratios for the four reporters, similar to the levels observed in non-transformed controls (Fig. 1). Only a few showed 2-4-fold signal ratios indicating the expression of the reporter proteins above the background signals. The frequency of the expressers could be estimated 1-3 among 40 transformants (2.5-7.5\%), which, nonetheless, is an improvement from the transformation using the pCXSN-GFP. This result indicates that the incorporation of Chlamydomonas introns can partly improve transgene expression in TISTR8447.

\section{Improving transgene expression in TISTR8447 using ble::E2A transcript fusion}

Previously, transcript fusion constructs using a self-cleavage $2 \mathrm{~A}$ peptide from foot-and-mouth disease virus (FMDV) [32] with ble selectable marker [33] were 


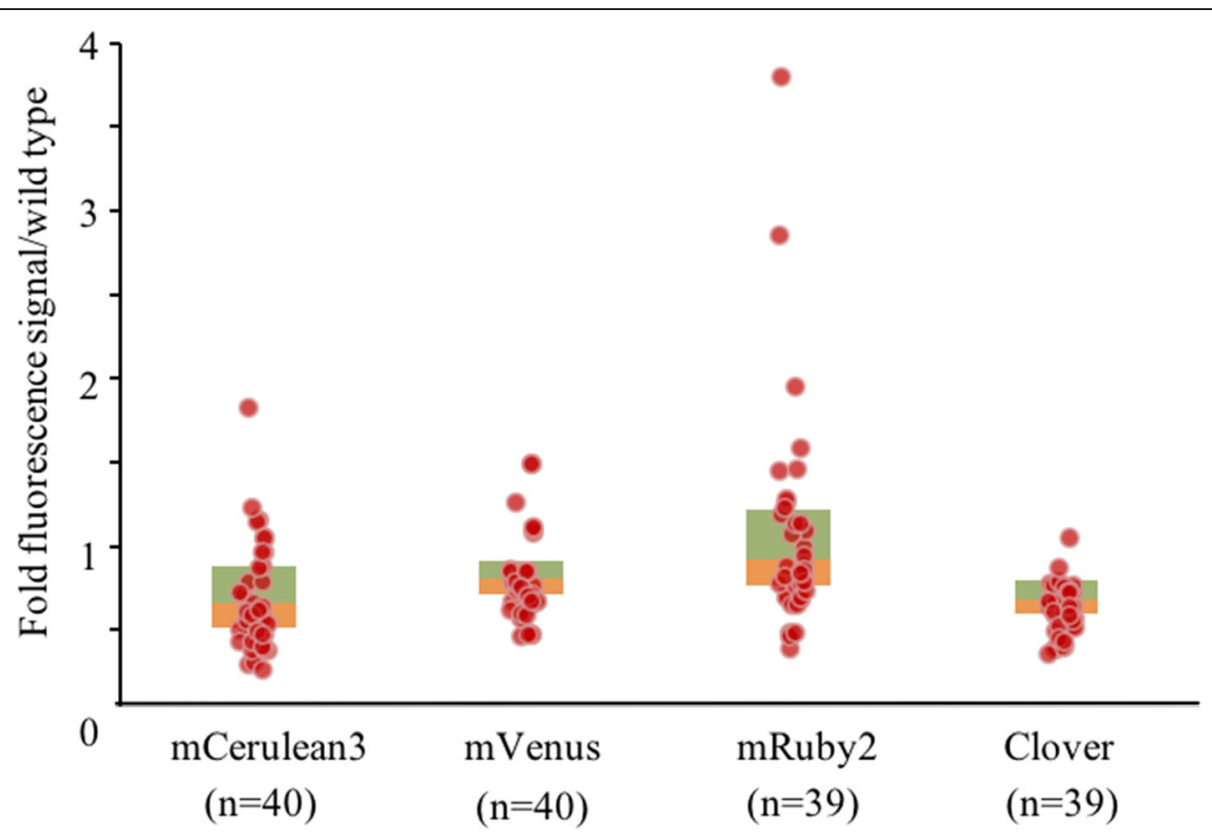

Fig. 1 Analysis of TISTR8447 transformants expressing four fluorescence reporter genes harboring Chlamydomonas introns using fluorescence microplate reader. Data are presented as box plots overlaid with scatter plots for fold fluorescence reads over the wild type values. $\mathrm{n}$ indicates the number of transformants reads for each reporter

shown to be a strategy of choices for highly efficient transgene expression in Chlamydomonas [23, 34-37]. To test whether this could improve transgene expression in TISTR8447, ble::E2A fusion vectors were constructed using with- or without-introns ble marker and mCherry reporter (pCreZ-intble::E2A-mCherry and pCreZ-ble::E2A-mCherry, Fig. 2 and Additional file 7). Transformants of these vectors were analyzed for the fluorescence reporter signal, and mCherry was readily observed under the confocal microscope (Fig. 2b). Fluorescence microplate analysis showed that most of the transformants from both constructs $(19 / 24$ or $79 \%$ for ble and $12 / 14$ or $85 \%$ for int-ble) had more than a 2 -fold increase of mCherry signal ratio to the wild type controls (Fig. 2c). The use of RBSC2 promoter and introns in the ble gene (int-ble) showed higher signals compared to that using PSAD promoter and ble gene without introns (ble), though without significant difference by Kruskal-Wallis Test $(p>0.05)$. This result indicates that the ble::E2A transcript fusion system could provide an efficient transgene expression system for the TISTR8447 under selective pressure of zeocin.

Subsequently, the expression level of the ble::E2A::mCherry transcript fusion was tested whether it could be induced in a dose-dependent manner with elevated zeocin concentrations. Selected transformants with low, medium and high expression were cultured in at $10 \mu \mathrm{g} \mathrm{ml}^{-1}$ zeocin, before transferring into the media supplemented with 0 $50 \mu \mathrm{g} \mathrm{ml}^{-1}$ zeocin for 2 days. However, no significant increase of the fluorescence signals following zeocin concentrations for both constructs was observed (Fig. 2d). At concentrations above $20 \mu \mathrm{g} \mathrm{ml}^{-1}$ zeocin, the transformants grew poorly with low cell mass and became chlorosis. This observation demonstrates that increases in zeocin selective pressure could not provide a further improvement on transgene expression in the TISTR8447.

\section{Improving transgene expression in TISTR8447 by UV mutagenesis}

To further improve the transgene expression, TISTR8447 mutants with enhanced transgene expression were generated using UV mutagenesis and a selection strategy using CRY1-1 (conferring emetine resistant) as reported by Neupert et al. [21]. Transformation of the TISTR8447 using pCRE-CRY1-1 was selected on the medium supplemented with $1 \mu \mathrm{g} \mathrm{ml}^{-1}$ emetine. Fifty selected transformants were tested on media supplemented with 1-20 $\mathrm{gg} \mathrm{ml}^{-1}$ emetine to confirm that they could grow on the medium supplemented with at most $1 \mu \mathrm{g} \mathrm{ml}^{-1}$ emetine. Three transformants (S14) were chosen for UV mutagenesis at $0.1 \%$ survival rate and subsequently selected using 2, 5 and $10 \mu \mathrm{g} \mathrm{ml}^{-1}$ emetine. Finally, three mutants (SUV1, 2 and 3), which were able to grow on $10 \mu \mathrm{g} \mathrm{ml}^{-1}$ emetine, were obtained (Fig. 3a). These mutants were then tested for any improvement on transgene expression by transformation using pOPT-mCerulean 3 followed by fluorescence microplate analysis (Fig. 3b). Although the highest levels of the fluorescence signal ratios were in the range of 2- to 3 -fold, which were similar to transformants of control 
$\mathbf{a}$
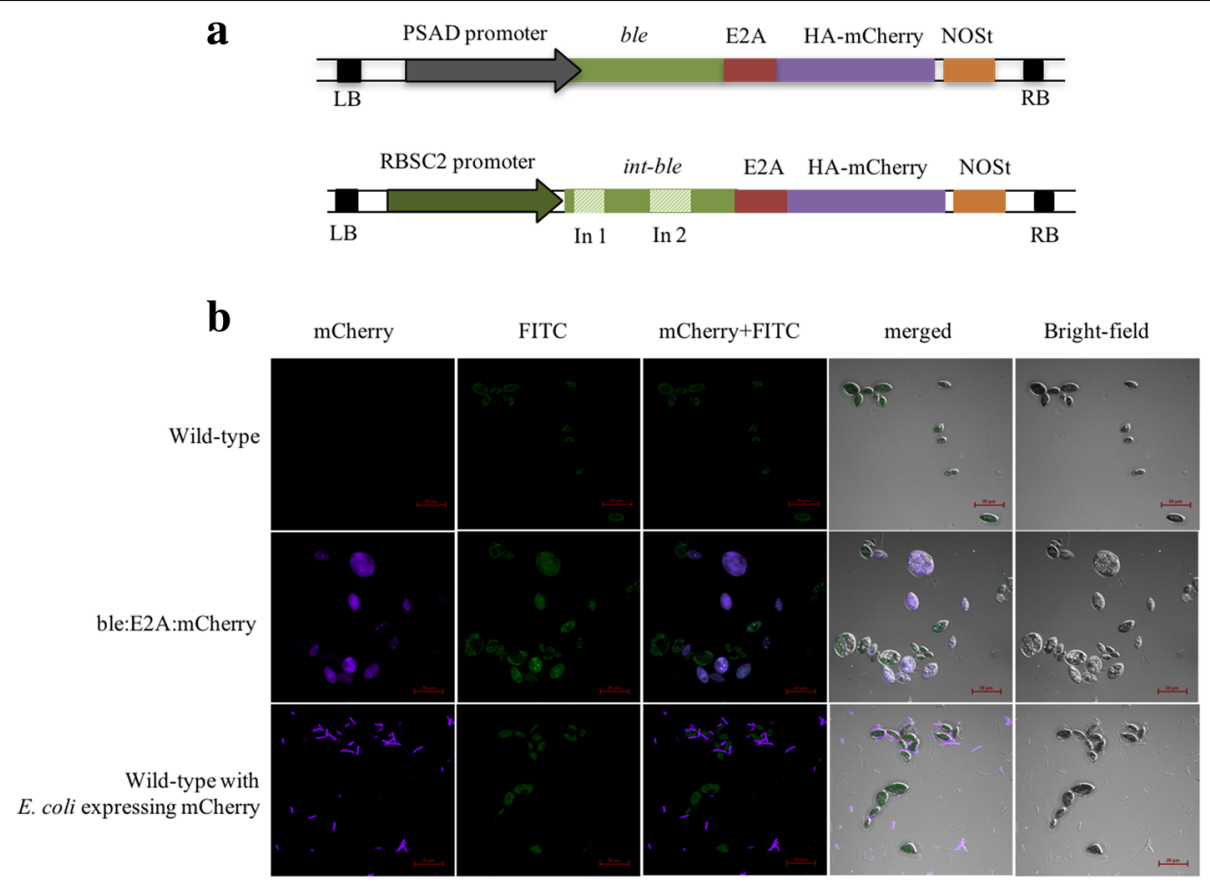

c

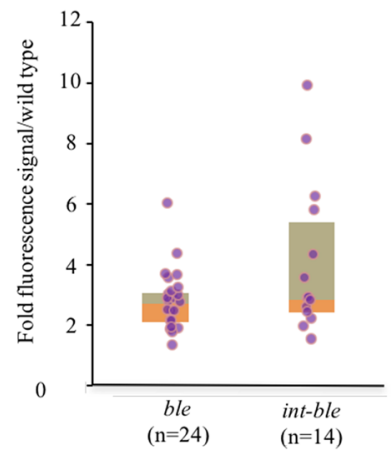

d

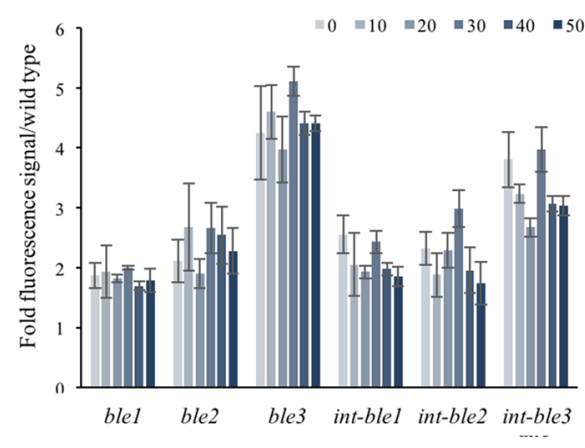

Fig. 2 Analysis of TISTR8447 transformants expressing transcript fusions. a pCreZ-ble::E2A::mCherry (ble) and pCreZ-intble::E2A.::mCherry (int-ble) vectors are illustrated. b TISTR8447 transformants analyzed by confocal microscopy showing mCherry signal and FITC channel-autofluorescence (scale bar $=20 \mu \mathrm{m}$ ). E. coli expressing $m$ Cherry was added to TISTR8447 wild type as a positive control. c mCherry signals of ble and int-ble vector transformants are presented as box plots overlaid with scatter plots. (n) indicates the number of transformants. $\mathbf{d}$ Fluorescence signals of low, medium and high mCherry expressors from each construct after subjected to media supplemented with 0-50 $\mu \mathrm{g} \mathrm{ml^{-1 }}$ zeocin for 2 days. Error bars represent standard deviations $(n=3)$

strains (S14), the SUV1-3 provided overall higher frequencies of transformants with high fluorescence signal ratios $(8 / 81$ or $10 \%, 5 / 43$ or $12 \%$ and $2 / 17$ or $12 \%$ for SUV1-3, respectively). This result demonstrates that although the level of transgene expression is only moderately improved, these TISTR 8447 mutants provide increases in the frequency of transgene expressed transformants.

Improving transgene expression by generating TISTR8447 white mutants and PSY::E2A transcript fusion

The transcript fusion system using ble::E2A have been shown so far to be the best improvement of transgene expression in TISTR8447, but the use of zeocin as a selective pressure is impractical for large-scale culture and affects the algal growth. To further improve this, an alternative expression strategy was developed by using Phytoene synthase (PSY) mutants, PSY gene complementation and light as a selective pressure. Chlamydomonas with PSY mutations were previously shown to exhibit pale-green or whitish colony, perish under the light as low as $8 \mu \mathrm{mol}$ photons $\mathrm{m}^{-2} \mathrm{~s}^{-1}$ and to be complemented by transformation using PSY gene [38]. By adopting this idea, white mutants of the TISTR8447 were generated by UV mutagenesis and selection of pale-green colonies grown in the dark. From 50 selection plates, each with 


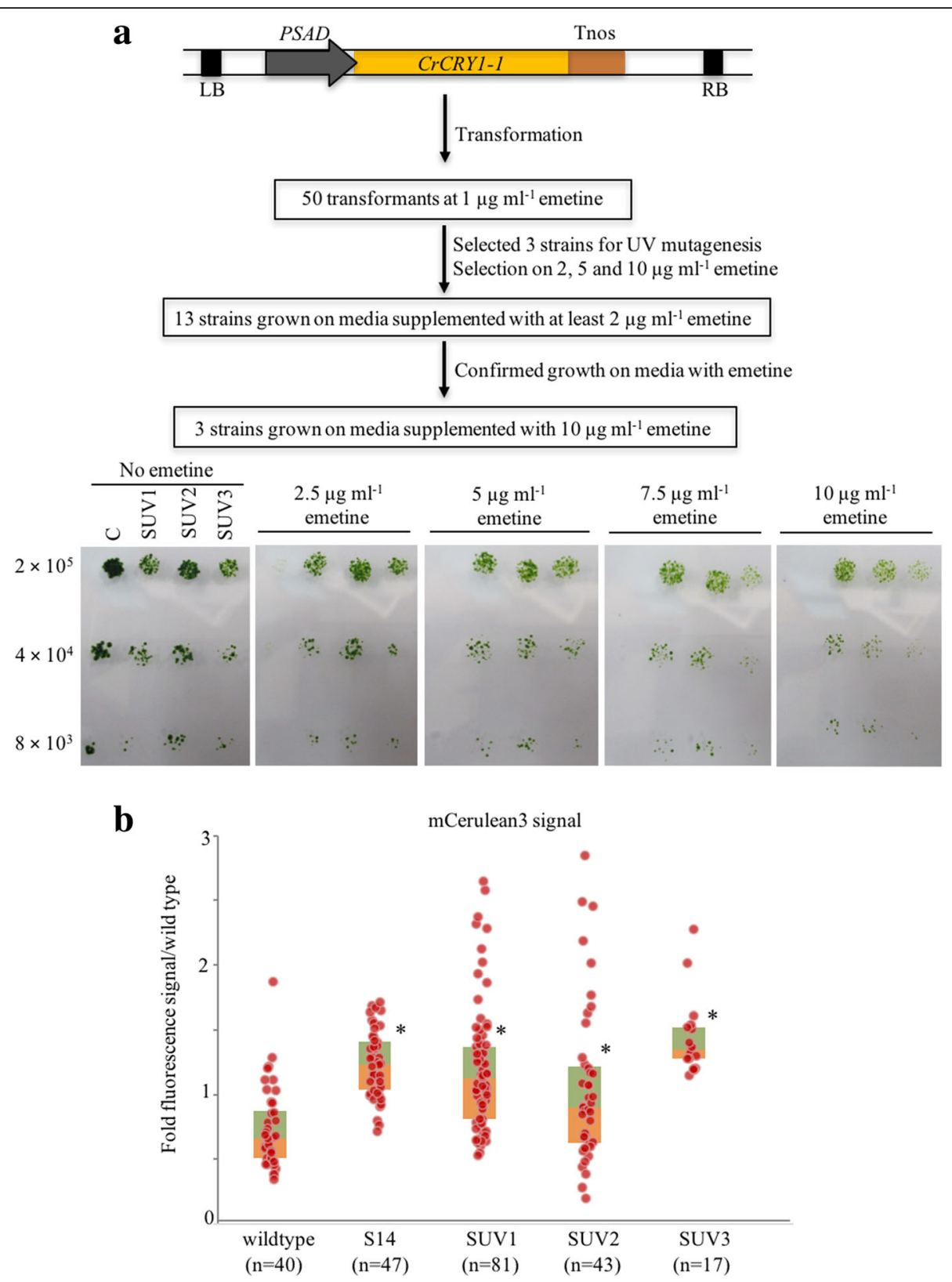

Fig. 3 UV mutagenesis and selection of SUV strains. a CrCRY1-1 expression construct and the experimental procedure for selecting transformants.

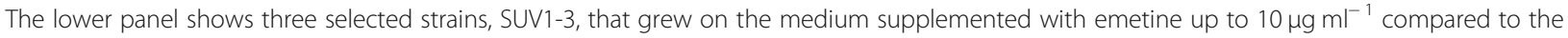
TISTR8447 wild type. $\mathbf{b}$ Box plots overlaid with scatter plots of mCerulean3 fluorescence signals of transformants generated from wild type, S14 (a CrCRY1-1 expressing strain) and SUV1-3. (n) indicates the number of transformants for each strain. Asterisks indicate significant differences between signals from transformants generated from wild type and others by Kruskal-Wallis Test $(p<0.05)$

$10^{6}$ cells, six white mutants, named G1-G6, were obtained after three rounds of subcultures in the dark (Fig. 4a). Four white mutants (G1, G2, G3 and G5) ceased growth under light at $50 \mu \mathrm{mol}$ photons $\mathrm{m}^{-2} \mathrm{~s}^{-1}$, similar to the cc4113 and cc4109 Chlamydomonas psy white mutants [38], while G4 and G6 mutants were able to grow under the light. After sequencing the PSY gene in these mutants, point mutations were observed in the PSY coding sequence in G1, G2 and G5 mutants (Fig. 4b), but not in G3. The G1, G2 and G5 psy mutants were then tested for complementation using a construct containing Chlamydomonas PSY coding sequence fused with $E 2 A$ and HA-mCherry. Transformation of these three white mutants using the Agrobacterium method was unsuccessful, and this may be because the mutant grew very slow and could not out-compete Agrobacterium growth. Electro-transformation yielded complementation from G1 and G2 mutants with green colonies after 
a Dark $\sim 50 \mu \mathrm{mol}$ photon $\mathrm{m}^{-2} \mathrm{~s}^{-1}$
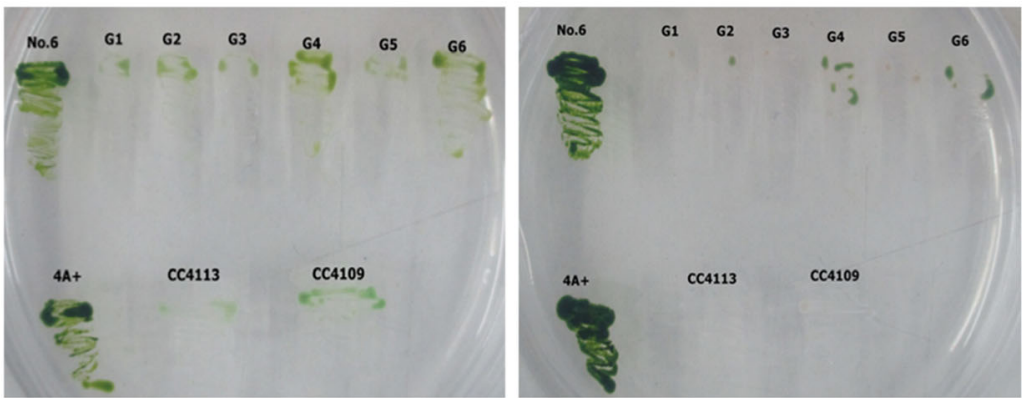

b

G5 734GCCC/CAT 761G/C PSY gene

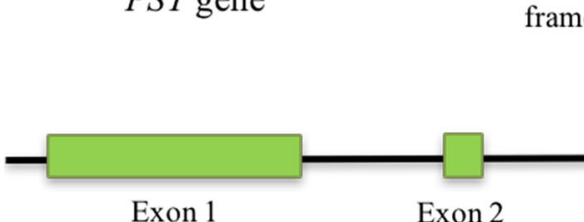

Exon 2

Exon 3 Exon 4

G1

1059CCGCCA/TTGCTA

immature stop

Exon 1 -shift

A $254 \mathrm{P}$

c

PSAD promoter

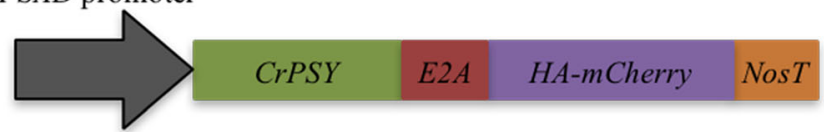

Exon 5

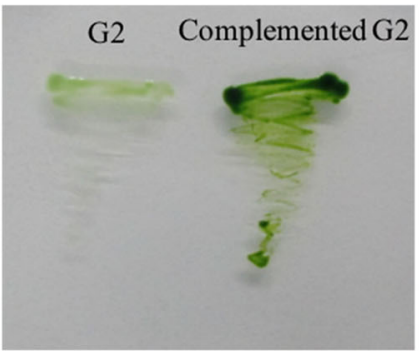

TAP/dark

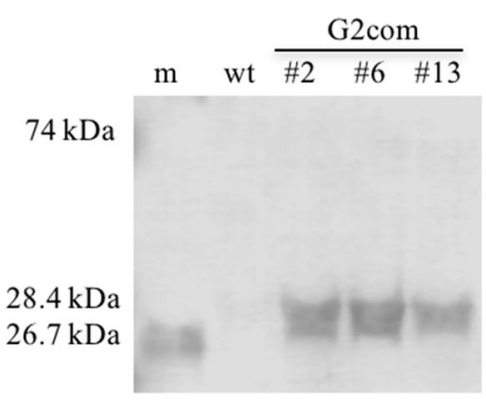

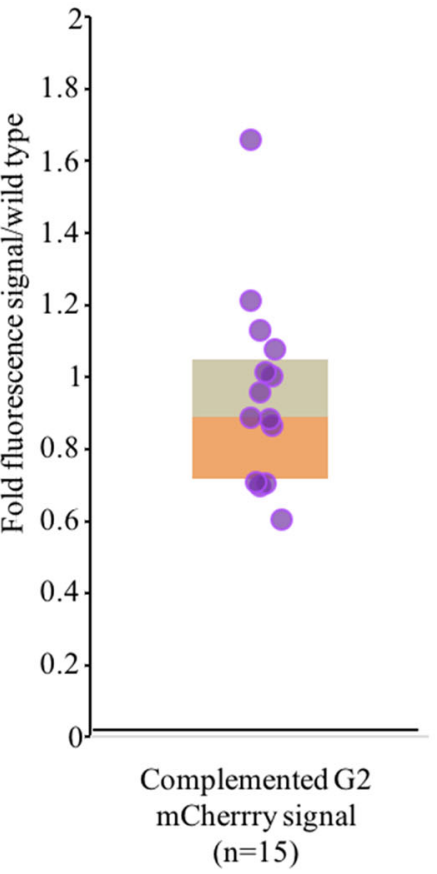

Fig. 4 Generation of psy white mutants and complementation using CrPSY. a Six isolated white mutants (G1-6) on TAP medium under light and dark conditions (No.6: TISTR8447, 4A+: Chlamydomonas, cC4113 and cc4109: Chlamydomonas psy white mutants). b Genotyping of psy mutants by direct PCR and sequencing. c Complementation of psy white mutants using CrPSY coding sequence fused in-frame with E2A and mCherry. mCherry was detected by both fluorescence microplate reader and immunoblot analysis ( $\mathrm{m}$ : mCherry from E. coli, wt: TISTR8447). mCherry carrying HA tag in the algae is $28.4 \mathrm{kDa}$, while that in E. coli is $26.7 \mathrm{kDa}$. A fainted band representing $74 \mathrm{kDa}$ of CrPSY::E2A::mCherry fusion protein was observed (see Additional file 8 for longer exposures and Additional file 10 for the full length blot) 
selection under light at $50 \mu \mathrm{mol}$ photons $\mathrm{m}^{-2} \mathrm{~s}^{-1}$ for $7-$ 10 days (Fig. 4c). However, the transformation rates were extremely low, approximately $1-4 \mathrm{CFU}$ per $5 \times 10^{6}$ cells per plate.

The G2 complemented strains were analyzed by fluorescence microplate reader and showed that most of the transformants had low levels of the fluorescence signals for mCherry (Fig. 4c). The frequency of the transgene expressers (up to a 2-fold signal ratio) was one among 15 transformants $(\sim 7 \%)$, somewhat similar to that of intron-containing vectors. Unlike that of ble::E2A vectors with the zeocin selection, the expression of PSY::E2A was still low. This may be because the PSY functions as an enzyme in carotenoid biosynthesis pathways, while ble protein functions by binding to zeocin in a direct proportion [23]. Therefore, light selection could not drive the PSY expression to the levels achieved by zeocin selection. Spontaneous revertants were also monitored in the transformation controls (without plasmid) and, so far, there were only two revertants observed among 40 selection plates $\left(5 \times 10^{6}\right.$ cells per plate). To preclude the possibility of these complemented strains being derived from revertants, mCherry expression was confirmed by immunoblot analysis (Fig. 4c). The non-cleaved PSY::E2A::HA-mCherry fusion protein was observed at a very low level indicating that the E2A peptide was efficiently self-cleaved in the TISTR8447 (Additional file 8). This result demonstrates that psy white mutants of TISTR8447 can be used as host cells for transformation using PSY selectable marker and light selection. However, the expression levels of the $P S Y:: E 2 A$ transgene were in the same range as that of constructs containing introns and far lesser than those using SUV mutants and ble::E2A with the zeocin selection, respectively.

\section{Growth and total lipid contents of SUV mutants and complemented white mutants}

To examine whether mutations for SUV and white mutants had any effect on growth or lipid production, the mutants were analyzed for growth curves and total lipid contents. While the growth of three complemented G2 strains and S14 was similar to that of the wild type, SUV1-3 grew slower (Fig. 5a). The cell growth of SUV1-3 was limited to approximately $10 \times 10^{6} \mathrm{cells}^{-}$ ${ }^{1}$, whereas the wild type could grow up to $15 \times 10^{6}$ cells $\mathrm{ml}^{-1}$. The lipid contents of S14 and G2 complemented strains in both $\mathrm{N}$-supplemented and $\mathrm{N}$-deprived media were similar to those of wild type, but those of SUV1-3 were significantly lower for both media $(p<0.05)$ (Fig. 5b). This result indicates that mutations, which provide improved transgene expression in SUV mutants, also affect physiological processes of the TISTR 8447 resulting in slow growth and less accumulated lipids.

\section{Discussion}

This work shows that Agrobacterium-mediated transformation is a convenient method for simultaneously testing the transformation of many microalgae. In this work, ten strains were tested, and six of them were successfully transformed. The best transformation rate was obtained from S. acutus TISTR8447 at $217.5 \pm 75 \mathrm{CFU}$ per $10^{6}$ cells, and this was selected as our best candidate for evaluating the transgene expression. Coelastrum, Chlorococcum, Monoraphidium and Tetradesmus are reported for their first trial here for the Agrobacterium method. Noting that although M. braunii, A. falcatus, A. densus and Coelastrum spp. were unable to be transformed in this work, this should not preclude their possibility to be transformed by other means. Agrobacterium-mediated transformation of microalgae was first introduced by Kumar et al. [30] for a successful transformation in Chlamydomonas, and various protocols have been developed since then to improve its efficiency $[9,39,40]$. It was then applied to many other microalgal species including Haematococcus pluvialis with the transformation rate at $153 \pm 4 \mathrm{CFU}$ per $10^{6}$ cells [41], Dunaliella bardawil at 39-42 CFU per $10^{6}$ cells [42], Schizochytrium at $50-170$ CFU per $10^{6}$ cells [43], Scenedesmus almeriensis at $90 \mathrm{CFU}$ per $10^{6}$ cells [26], Dunaliella salina at $40 \pm 5$ CFU per $10^{6}$ cells [29] and Tetraselmis chuii at $150 \pm 90 \mathrm{CFU}$ per $10^{6}$ cells [27]. And, with a different unit of transformation rate, Nannochloropsis sp. [44], Chlorella vulgaris [45] and Ankistrodesmus sp. [46] were shown to be transformed based on GUS expression at approximately 21,30 and $3.5 \%$ efficiency, respectively. Taken together, this work provides support for the use of the Agrobacterium-mediated method for transforming other potential industrial microalgae yet to be tested.

Extremely inefficiently transgene expression is commonly observed in microalgae [9], and this appears to be the case for Scenedesmus as indicated by this and previous works. For example, transformation of S. almeriensis yielded little or very low GUS reporter expression even after screening many transformants [26], that of S. bajacalifornicus had only $2.96 \%$ of transformants with detectable GUS staining [46] and that of S. obliquus also showed only $1.5 \%$ of the transformants with GFP expression [25]. In our case, no GFP expression was observed at neither transcript nor protein level. Our attempt to improve the transgene expression in TISTR 8447 by using tools based on Chlamydomonas, so far, shows that the transcript fusion using ble::E2A provided the highest improvement with up to 10 -fold increases of mCherry expression and up to $85 \%$ of transformants with observable mCherry. However, other strategies including the uses of intron-containing constructs, SUV1-3 mutants and white mutants with PSY::E2A complementation provided only minor improvements with at most 2-4-fold increases of the reporter expression. The majority of the 

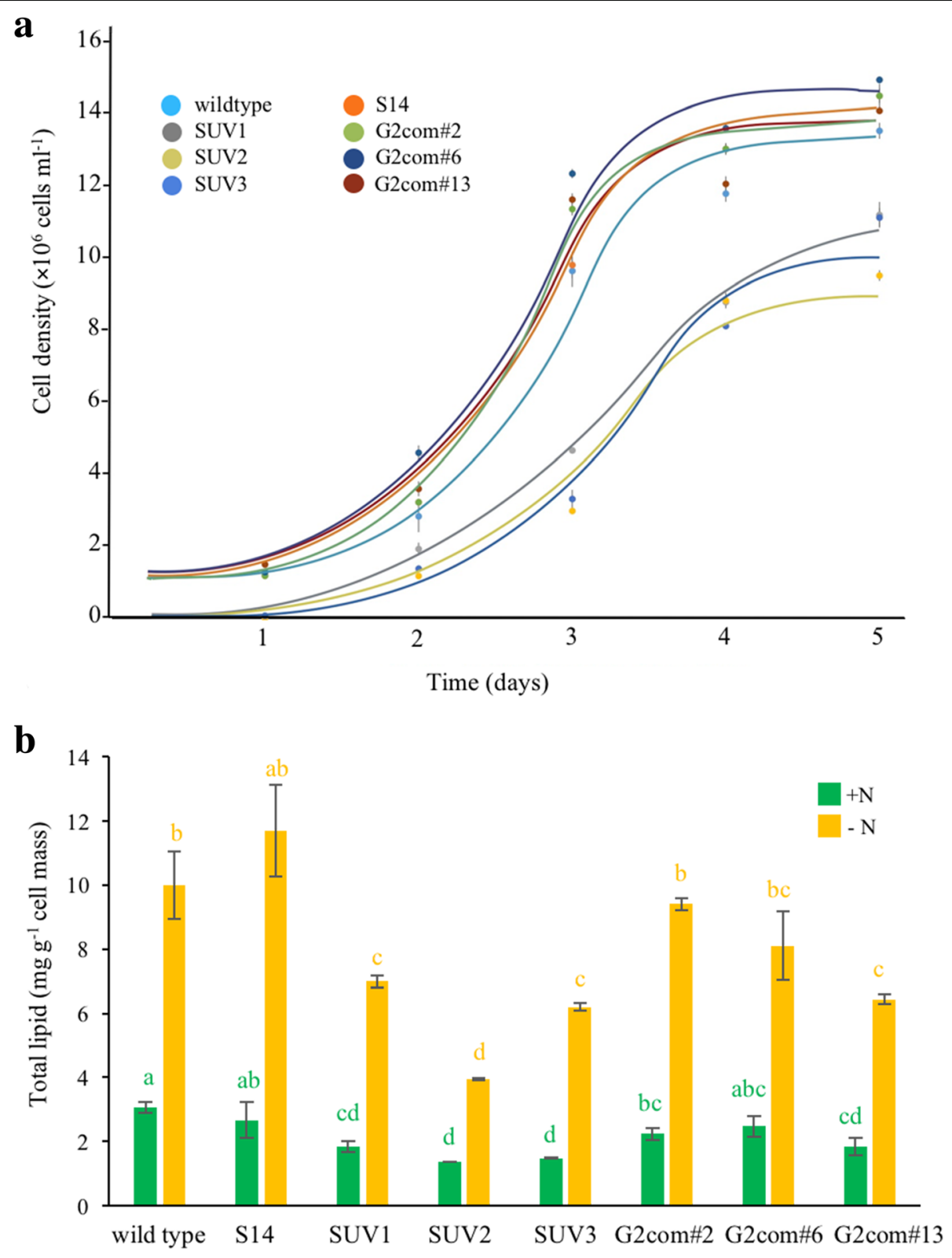

Fig. 5 a Growth curves of S14, SUV1-3 and complemented G2 strains compared to TISTR8447 wild type. $\mathbf{b}$ Total lipid content of the microalgae in $\mathrm{N}$-supplemented and $\mathrm{N}$-deprived media grown for 3 days. Error bars represent standard deviation $(n=6)$, and bars with the same letter are not significantly different (Tukey's test, $p<0.05$ )

transformants from the intron-containing constructs and the white mutants had very low transgene expression, while SUV mutants had increases in the frequency of transgene expressors.

Transcriptional gene silencing was proposed to be the key factor that causes the low transgene expression in Chlamydomonas [13, 19, 21, 36, 47] and most likely in many other microalgae [48-50]. Noting that a recent work by Mini et al. [9] reported that rearrangements of transgenes could also be another factor contributing to the inefficient expression in Chlamydomonas. Because gene expression tools that could circumvent the gene silencing effects were successfully developed in Chlamydomonas, these tools could be applied to other microalgae, particularly in the TISTR8447. However, the improvements were far less than those obtained in Chlamydomonas. The development of the ble:: $2 A$ systems provided more than a 100-fold improvement of transgene expression in Chlamydomonas [23, 34, 35, 37], while it was only a 10 -fold increase in the TISTR8447. Insertions of an endogenous intron(s) into transgenes or the surrounding $5^{\prime}$ and $3^{\prime}$ untranslated regions led to improved transgene expression in 
Chlamydomonas [51-53]. In contrast, these Chlamydomonas introns only provided small increases in the transgene expression in the TISTR8447. A little improvement in the TISTR 8447 observed here by the use of the introns could be because of the difference in intron splicing between the species, or these introns could only occasionally help the transgene escaping the silencing controls in the TISTR8447. Perhaps, Scenedesmus might have a more robust gene silencing mechanism than that in Chlamydomonas.

Neupert et al. [21] first reported the strategic isolation of Chlamydomonas mutants with improved transgene expression using CRY1-1 and elevated emetine concentrations for selection. The selected mutants, UVM4 and UVM11, had demonstrated up to 100-fold increases in emetine resistant. Less than expected, our selections of mutagenized TISTR8447 yielded up to a 10-fold increase in emetine resistance, and the expression levels based on the fluorescence ratios were improved only up to a 2-fold. Nonetheless, the SUV1-3 had higher frequencies of transgene expressors, in which transformants with at least a 2 -fold signal could be accounted for 10-12\% compared to $\sim 2.5 \%$ observed in wild type. This improvement is somewhat comparable to UVM4 and UVM11 that provided 4.5-fold increases in the frequency of transgene expressors compared to the wild type [47].

MET1 (DNA methyltransferase1) is one of the key enzymes for the DNA methylation transgene silencing along with other DNA-methylation independent gene silencing enzymes [13]. Chlamydomonas met1 insertional mutants were shown to provide an improvement for transgene expression. Work from Kurniasih et al. [13], which performed UV mutagenesis using the met1 mutant and selection using Neupert et al. [21] selection method, yielded mutants with even higher transgene expression. Because only moderate improvement was achieved in the SUV mutants, it is likely that there are still other transcriptional silencing genes present in the TISTR8447. Further mutations in the transcriptional silencing related genes may be required for further improvement.

Mutations that provide improved transgene expression in Chlamydomonas are known to be associated with epigenetic controls, and these may affect cell growth, as demonstrated in Chlamydomonas UVM mutants of the met-1 insertional mutant [13]. Indeed, mutations of SUV1-3 are most likely related to epigenetic control machinery, and they affect both cell growth and lipid production, as none of these effects was observed in the S14 control strain. This result shows that while the SUV1-3 mutants have gained some improvement on the transgene expression, their growth and ability to accumulate lipids were weakened, compromising cell mass and lipid production. This result confirms the previous observation of the negative aspect of using mutants related to epigenetic controls.
Thus, cautions should be made before performing genetic screening for enhancing transgene expression, especially when the cell performances are the key to the application. Nonetheless, the white mutants, when complemented, could provide sufficiently intact growth and have only slight decreases in the lipid content. The result also suggests that while $C r P S Y$ can sufficiently complement the SaPSY knockout, yielding complemented strains with robust cell growth, it could not provide the lipid accumulation as efficient as the $S a P S Y$.

Even though the $P S Y:: E 2 A$ construct is not as effective as ble::E2A in forcing expression, this system provides an alternative selectable marker for microalgae. Current selectable markers used for microalgae transformation are based on antibiotic selection, for example, bleomycin/ zeocin resistance gene [33] and paromomycin resistance gene [54]. Recently, the herbicide norflurazon was recently developed for transformation selection using Phytoene desaturase (PDS) with an amino substitution L505F in some microalgae [55-57]. The use of PSY gene as a selectable marker for microalgae, so far, has not been reported. This may be because of two main reasons: white mutants needed to be generated by mutagenesis and screened for each microalga, and white mutants are weak with slow growth and difficult to transform. For the work presented here, this is one of the most economical transgene selection approaches as only a light source is required. This selectable marker is compatible with an outdoor and large-scale culture as transgene constructs can be maintained by sunlight.

To this end, among the Chlamydomonas gene expression tools tested, the transcript fusion using ble::E2A appeared to be the most efficient and could instantaneously mitigate the inefficient transgene expression in microalgae, in particular, the TISTR8447. However, the exposure of zeocin antibiotic to the algal cells generally results in cell toxicity and affects cell growth and potentially the production of products and yields [58]. Furthermore, the use of zeocin is uneconomical for large-scale production, limiting the use of ble::E2A system. A consensus for inefficient transgene expression has been evidenced in many oleaginous microalgae and Scenedesmus species as reported here. The challenges in gaining high transgene expression in microalgae are the critical bottleneck for current development in Eukaryotic microalgal biotechnology. Further improvements and newly developed tools are critically needed to allow efficient use of microalgae for biotechnology application.

\section{Conclusions}

This work demonstrates that oleaginous microalgae isolated from natural resources can be screened for selecting strains with high transformation efficiency, but they 
generally have a low capacity for transgene expression. A selected strain, S. acutus TISTR8447, was tested to improve the transgene expression using strategies developed in Chlamydomonas, but overall improvement was of moderate for both levels and frequency of expression. So far, the most effective tool giving the highest improvement is the transcript fusion using ble::E2A system. Furthermore, a new strategy for transgene expression has been developed using $p s y$ white mutants with an expression vector containing PSY::E2A for complementation and light selection. Finally, this work demonstrates that genetic engineering of non-model microalgae is still a challenging task. New tools and strategies are critically needed for transgene expression in promising industrial microalgae.

\section{Methods}

\section{Microalgae and cultivation conditions}

Microalgae were obtained from Thailand Institute of Science and Technological Research (TISTR) including Coelastrum sp. (TISTR8511), Scenedesmus acutus (TISTR8555), S. acutus (TISTR8540), S. acuminatus (TISTR8519), S. acutus (TISTR8447), Chlorococcum humicola (TISTR8434), Monoraphidium braunii (TISTR8429), Ankistrodesmus falcatus (TISTR8557), Tetradesmus cumbricus (TISTR8480), Ankistrodesmus densus (TISTR8505). These accessions were chosen based on their potential high accumulation of lipid droplets under the $\mathrm{N}$ deprivation condition and the variation of algal species. Chlamydomonas white mutants CC4113 (Its1-207 mt+) and CC4109 (Its1-203 mt+) were obtained from Chlamydomonas Resource Center. Microalgae were cultured in either Tris-acetate phosphate (TAP) or BG-11 media at $25^{\circ} \mathrm{C}$ under continuous light $\left(50 \mu\right.$ mol photons $\mathrm{m}^{-}$ ${ }^{2} \mathrm{~s}^{-1}$ ), excepting that those white mutants were incubated in the dark. The N-deprived medium (TAP-N) was prepared by substituting $\mathrm{KNO}_{3}$ with $\mathrm{KCl}$. For growth analysis, three cultures of $50 \mathrm{ml}$ were started at the of $10^{6}$ cells ml ${ }^{-1}$ cell density, and $1 \mathrm{ml}$ sample was collected daily to monitor for cell density.

\section{Plasmid constructions}

pOPT vector series with reporter genes including mRuby2, mCerulean3, mVenus and Clover [22] were obtained from Chlamydomonas Resource Center. pCXSNGFP was constructed by TA cloning using the Agrobacterium transformation vector pCXSN [59] and GFP coding sequence, which was PCR amplified using GFP-F and GFP-R primers (Additional file 9). Transcript fusion vectors were constructed using pPLV02 [60] as the vector backbone. The pPLV02 backbone was amplified using pplv-F and pplv-R primers. PSAD promoter, RBSC2 promoter-ble with introns and ble without intron fragments were amplified from pSL18 [61, 62] using psad-F and psad-R primers, pSP124S [51] using rbcs-F and Zeo-E2A-R primers and pICZ (Thermo Fisher) using Zeo-F and Zeo-E2A-R primers, respectively. Each primer has an adaptor sequence for subsequent sequence and ligation independent cloning (SLIC) [63]. All PCR cloning was performed using hi-fidelity Q5 DNA polymerase (New England Biolabs, USA). pCreZ-E2A and pCreZint-E2A were constructed by fusing the pPLV02 PCR fragment with PSAD promoter and ble without intron, and RBSC2 promoter-ble with introns, respectively, by SLIC technique. HA-mCherry was subsequently inserted into both vectors at NcoI site by PCR amplification using HA-mcherry-F and mcherry- $\mathrm{R}$ primers and SLIC.

For $C r C R Y 1-1$ expression construct, the coding region of CrCRY1 was PCR amplified from Chlamydomonas cDNA using gene specific primers, before being re-amplified using a reverse primer with a modified base at the last codon from CTG to CCG (cry1-1-F and cry1-1-TtoC-R primers) to generate CrCRY1-1 coding sequence. The CrCRY1-1 fragment with adaptor sequences was then inserted into pCreZ-E2A at EcoRI and BamHI sites by SLIC, removing ble-E2A. For CrPSY::E2A:: $m$ Cherry constructs, the CrPSY coding sequence was PCR amplified from Chlamydomonas cDNA and re-amplified using crpsy-F and crpsy- $\mathrm{R}$ primers, which contain adaptor sequences for SLIC. The CrPSY fragment was then ligated to a vector fragment, which was amplified from pCreZ-E2A by E2A-F and psad-crpsy- $\mathrm{R}$ primers, replacing ble coding sequence and in frame with E2A. Plasmids for Agrobacterium-mediated transformation were transferred into Agrobacterium cells by electroporation.

\section{Transformation}

The microalgal strains were tested for their sensitivity to hygromycin B before performing an Agrobacterium-mediated transformation. Briefly, $10^{6}$ cells were spread onto TAP or BG-11 agar media supplemented with 10$100 \mu \mathrm{g} \mathrm{ml}^{-1}$ of hygromycin B for 14 days. This sensitivity test was performed in triplicate. For Agro-transformation, microalgae were cultured in liquid media for 3-4 days, and $10^{6}$ cells were grown on solid media for 2-3 days until forming a lawn. A. tumefaciens EHA105 harboring transformation plasmids were grown in LB media supplemented with $25 \mu \mathrm{g} \mathrm{ml}^{-1}$ of rifampicin and $50 \mu \mathrm{g}$ $\mathrm{ml}^{-1}$ of kanamycin under continuous shaking at $28^{\circ} \mathrm{C}$ for 2 days. For evaluation of Agrobacterium strains, A41, GV3101 and LBA4404 strains were used in replacement of EHA105. The algal lawn was mixed with $100 \mu$ lof Agrobacterium $\left(\mathrm{OD}_{600}=1\right)$ using a spreader and co-cultivated in the dark for 2 days before transferring onto solid TAP or BG-11 selective media supplemented with $250 \mu \mathrm{g} \mathrm{ml}^{-1}$ cefotaxime and hygromycin B at specific concentrations. Colonies obtained from selection plates were subcultured twice on the selection media 
before being designated as transformants. Transformation rates were calculated based on the numbers of resistant colonies per $10^{6}$ starting cells. Agrobacterium cells without expression plasmid were used for transformation as negative controls.

For electro-transformation, log phase cells at no more than $2 \times 10^{6}$ cells ml $^{-1}$ were harvested by brief centrifugation at $400 \times \mathrm{g}$ and resuspended in TAP supplemented with $40 \mathrm{mM}$ sucrose (TAP sucrose) at $2 \times 10^{8} \mathrm{cells}^{-1}$. Thirty-eight microlitres of the algal suspension were mixed with $2 \mu \mathrm{l}$ of a plasmid vector (400 $\mathrm{ng}$ ) before transferring to a $2 \mathrm{~mm}$ gap electroporation cuvette and pulsing using Bio-Rad Gene Pulser II with the following condition: $0.4 \mathrm{kV}, 25 \mu \mathrm{F}$ and $500 \Omega$. The algal cells were immediately transferred to $10 \mathrm{ml}$ TAP sucrose and cultured at the normal condition with constant shaking at $100 \mathrm{rpm}$ under low light for an overnight before spreading onto TAP agar supplemented with $30 \mu \mathrm{g} \mathrm{ml}^{-1}$ of paromomycin or $10 \mu \mathrm{g} \mathrm{ml}^{-1}$ of zeocin for 7-10 days.

For the transformation of white mutants, a white colony was cultured in TAP sucrose with constant shaking in the dark up to 10 days or until reaching $1-2 \times 10^{6}$ cells $\mathrm{ml}^{-1}$. Cells were harvested and resuspended in 40 $\mathrm{mM}$ sucrose TAP at $2 \times 10^{8}$ cells $\mathrm{ml}^{-1}$. Subsequently, $38 \mu \mathrm{l}$ of the suspension was mixed with $2 \mu \mathrm{l}$ of a plasmid before being electroporated using the same condition as above and cultured in $10 \mathrm{ml}$ TAP sucrose for overnight with constant shaking in the dark. The cells were plated onto TAP agar and incubated in the dark for 5 days and then under light $\left(50 \mu \mathrm{mol}\right.$ photons $\left.\mathrm{m}^{-2} \mathrm{~s}^{-1}\right)$ for $7-10$ days.

\section{UV mutagenesis and mutant screening}

UV mutagenesis was performed by irradiating the TISTR8447 at a density of $5 \times 10^{6}$ cells $\mathrm{ml}^{-1}$, which were previously kept in the dark for $2 \mathrm{~h}$, in a petri dish using a UV transilluminator for $2 \mathrm{~h}$ to obtain a $0.1 \%$ survival rate. Cells were cultured overnight with shaking in the dark before plating onto TAP agar medium at $10^{6}$ cells per plate. For SUV mutants, CRY1-1 transformants were UV irradiated and plated onto TAP agar medium supplemented with emetine at 2, 5 and $10 \mu \mathrm{g} \mathrm{ml}^{-1}$. For white mutants, irradiated cells were plated onto TAP agar medium and incubated in the dark for 14 days. Colonies with pale-green were subcultured in the dark.

\section{Molecular characterization}

For DNA and RNA isolation, the algal cells were subjected to a mechanical disruption in liquid nitrogen using a mortar and pestle. DNA was isolated using the CTAB method, whereas total RNA was isolated using GENEzol TriRNA Pure Kit (Geneaid, Taiwan). RNA was purified by using RNase-free DNase and RNA Cleanup Kit. cDNA was synthesized using one microgram of total
RNA by MMuLV reverse transcriptase. PCR and RT-PCR reactions were performed using Taq DNA polymerase and primers listed in Additional file 9. For sequencing of the PSY coding sequence of TISTR8447 (Genbank accession MF401544), SaPSY of the white mutants was amplified from total DNA using hi-fidelity Q5 DNA polymerase and sapsy-seq-F and sapsy-seq- $R$ primers and sequenced.

For western analysis, a total protein was isolated by grinding the cells with liquid nitrogen and resuspended in a protein extraction buffer $[20 \mathrm{mM}$ Tris- $\mathrm{HCl} \mathrm{pH} 8.0,150 \mathrm{mM}$ $\mathrm{NaCl}, 2 \mathrm{mM}$ EDTA, 10\% ( $v / \mathrm{v})$ glycerol, 0.5\% IGEPAL CA-360 and $1 \mathrm{mM}$ PMSF]. The total protein was quantified by Bradford assay before subjecting to SDS-PAGE and blotting onto a PVDF membrane. mCherry was detected using rabbit anti-mCherry as a primary antibody at 1:1000 dilution and anti-rabbit-HRP as a second antibody at 1:10,000 dilution. The western signal was detected using WesternSure Premium Chemiluminescence Substrate (Li-COR, USA) and C-DiGit Blot Scanner (Li-COR, USA).

\section{Fluorescence detection}

Fluorescent reporter signals were analyzed using a microplate reader. The excitation and emission wavelengths are as follows; mRuby2 (ex $=558 \mathrm{~nm}$, em $=605 \mathrm{~nm}$ ), mCerulean 3 $(\mathrm{ex}=445 \mathrm{~nm}, \mathrm{em}=503 \mathrm{~nm})$, mVenus $(\mathrm{ex}=515 \mathrm{~nm}, \mathrm{em}=$ $550 \mathrm{~nm}$ ), Clover $(\mathrm{ex}=477 \mathrm{~nm}, \mathrm{em}=515 \mathrm{~nm})$, mCherry $(\mathrm{ex}=$ $562 \mathrm{~nm}, \mathrm{em}=607 \mathrm{~nm}$ ). Chlorophyll autofluorescence was measured at $440 \mathrm{~nm}$ for excitation and $685 \mathrm{~nm}$ for emission. Standard curves for the conversion of fluorescence signal to protein contents were generated from recombinant GST-mCerulean and GST-mCherry purified from E. coli and quantified using Bradford assay. The protein concentrations used was $1.25-400 \mathrm{ng}^{-1}$ in the TISTR8447 algal culture at $10^{6}$ cells $\mathrm{ml}^{-1}$. The chlorophyll fluorescence was used for calculating the cell number based on a standard curve between the chlorophyll signals and cell numbers. Selected transformants with a high level of expression of transgenes were then assessed for fluorescence signal using Nikon C2 Si confocal microscopy.

\section{Stability test}

Transformants were maintained on media without hygromycin B for 2 weeks before subculturing onto media with and without hygromycin B to determine the retention of the selectable marker gene without the selection pressure. For the G2 complemented lines, the dark and light conditions were used instead of the antibiotic. These subcultures were repeated every 2 weeks.

\section{Lipid quantification using vanillin method}

This lipid quantification using vanillin was modified from Mishra et al. [64]. Cells were grown in a starting culture using liquid TAP medium for 2-3 days $\left(\sim 2 \times 10^{6}\right.$ cells ml $^{-1}$ 
concentration) before dividing in half, and the medium of each half was replaced by liquid TAP or TAP-N at $2 \times 10^{6}$ cells $\mathrm{ml}^{-1}$ concentration before culturing for 3 days. Approximately $1.5 \times 10^{6}$ cells with known mass was mixed with $200 \mu \mathrm{l}$ sulfuric acid, incubated at $95^{\circ} \mathrm{C}$ for $10 \mathrm{~min}$ before placing on ice for $5 \mathrm{~min}$, added with $500 \mu \mathrm{l}$ phospho-vanillin $[0.12 \%(w / v)$ vanillin in $80 \%(v / v)$ phosphoric acid] and incubated at $37^{\circ} \mathrm{C}$ for $15 \mathrm{~min}$. The solution was briefly centrifuged at $3000 \mathrm{rpm}$ for $5 \mathrm{~min}$, and the absorbance at $530 \mathrm{~nm}$ of the sample was assessed. Total lipid was quantified against the standard curve generated from canola oil.

\section{Nile red staining}

Microalgae were stained using Nile red $\left(10 \mu \mathrm{g} \mathrm{ml}^{-1}\right.$ in DMSO) and Calcofluor (1\%) for $30 \mathrm{~min}$ in the dark at $25^{\circ} \mathrm{C}$. The samples were then fixed in $4 \%$ paraformaldehyde before washing twice with PBS solution and analyzed using Nikon C2 Si confocal microscopy (543 nm excitation, 525-605 $\mathrm{nm}$ emission).

\section{Statistical analysis}

The statistical tests used for analyzing the data varied based on the distribution of each data set. Kruskal-Wallis test was conducted to assess the difference in the transformation efficiency of different Agrobacterium strains and the levels of fluorescence signals among populations of microalgal strains. For datasets with a normal distribution, one-way analysis of variance (ANOVA) using an alpha of 0.05 and a multiple range test using Tukey's method was conducted.

\section{Additional files}

Additional file 1: Survival of ten microalgal strains on different concentrations of hygromycin B. (PDF $37 \mathrm{~kb}$ )

Additional file 2: Representative cultured and selective plates for Agrobacterium-mediated transformation of TISTR8540. (PDF $552 \mathrm{~kb}$ )

Additional file 3: A transgene stability test of TISTR8540 and TISTR8447. (PDF $1536 \mathrm{~kb}$ )

Additional file 4: Nile red staining of the TISTR8447 after 3 days of nitrogen starvation. (PDF $101 \mathrm{~kb}$ )

Additional file 5: Transformation rates of the TISTR8447 using four Agrobacterium strains. (PDF $39 \mathrm{~kb}$ )

Additional file 6: Agrobacterium-mediated transformation of S. acutus TISTR8447. (PDF $446 \mathrm{~kb}$ )

Additional file 7: The schematic of pCreZ vectors. (PDF 64 kb)

Additional file 8: Western analysis of CrPSY::E2A::mCherry fusion protein with extended exposure times. (PDF $127 \mathrm{~kb}$ )

Additional file 9: Oligonucleotide primer sequences. (PDF $111 \mathrm{~kb}$ )

Additional file 10: The full length immuno blot of G2 complemented strains. (PDF $170 \mathrm{~kb}$ )

\section{Abbreviations}

ANOVA: Analysis of variance; aphIV: Hygromycin phosphotransferase;

BG11: Blue-green Medium; ble: Bleomycin resistant protein;

CaMV: Cauliflower mosaic virus; CFU: Colony forming unit;

CrPSY: Chlamydomonas reinhardtii phytoene synthase; CRY1-1: Cryptochrome circadian clock 1-1; CTAB: Cetyltrimethylammonium bromide; DMSO: Dimethyl sulfoxide; EDTA: Ethylenediaminetetraacetic acid; GFP: Green fluorescence protein; GST: Glutathione S-transferase; GUS: Betaglucuronidase; HA: Hemagglutinin; HRP: Horseradish peroxidase; MET1: DNA methyltransferase1; MMuLV: Reverse transcriptase: moloney murine leukemia virus reverse transcriptase; PDS: Phytoene desaturase;

PMSF: Phenylmethylsulfonyl fluoride; PSY: Phytoene synthase;

PVDF: Polyvinylidene fluoride; SaPSY: Scenedesmus acutus phytoene synthase; SDS-PAGE: Sodium dodecyl sulfate polyacrylamide gel electrophoresis;

TAP: Tris-acetate phosphate buffer; TAP-N: Tris-acetate phosphate buffer without nitrogen; Taq polymerase: Thermus aquaticus polymerase; UV: Ultraviolet

\section{Acknowledgments}

We are grateful to the Thailand Institute of Scientific and Technological Research (TISTR) for providing the microalgae. We thank Pornthip Boonmahamongkol and Science Equipment center, Faculty of Science, Kasetsart University for equipment and technical support, particularly fluorescence microplate reader and confocal microscopy. We thank Dr. Thidaporn Supapakorn for support on statistical analysis. We thank Dr. Kunn Kangwansaichol, Chanakarn Chaikaeodang, Jureeporn Konpiewlert and Chanarong Sartsanga for technical support.

\section{Funding}

This work was supported by Kasetsart University Research and Development Institute (KURDI), PPT Public Company Limited and Thailand Research Fund (TRF-RSA6080031). These funding bodies had no role in the design of this study or any role during the collection, analysis, and interpretation of the data, and in writing the manuscript.

\section{Availability of data and materials}

All data generated or analyzed during this study are included in this published article (and its Additional files) and are available from the corresponding author on reasonable request. Microalgae are stocked at the Thailand Institute of Science and Technological Research (TISTR). The PSY coding sequence of TISTR8447 is available at Genbank (accession MF401544).

\section{Authors' contributions}

ASu and SV conceived and designed the experiments. ASu, WP, TK, SSr, SSa and WD performed experiments. ASu, ASi, PJ, KJ and SV analyzed the data. ASu and SV prepared the Figures and Tables and wrote the manuscript. ASi, PJ and SV corrected and proofread the manuscript. All authors read and approved the final manuscript.

Ethics approval and consent to participate

Not applicable.

\section{Consent for publication}

Not applicable.

\section{Competing interests}

This research was partly supported by PPT Public Company Limited (Thailand). Kanidtha Jariyachawalid is employed by the PTT public company limited. Patent applications (Thailand patent No.1501003942 and No.1601007906) have been filed for some of the technology disclosed in this publication. All other authors declare no competing interests.

\section{Publisher's Note}

Springer Nature remains neutral with regard to jurisdictional claims in published maps and institutional affiliations.

\section{Author details}

${ }^{1}$ Special Research Unit in Microalgal Molecular Genetics and Functional Genomics (MMGFG), Department of Genetics, Faculty of Science, Kasetsart University, 50 Ngam Wong Wan road, Chatuchak, Bangkok 10900, Thailand. ${ }^{2}$ Center of Advanced studies for Tropical Natural Resources, Kasetsart University, 50 Ngam Wong Wan road, Chatuchak, Bangkok 10900, Thailand. ${ }^{3}$ PTT Research and Technology Institute, PTT Public Company Limited, Ayuthaya 13170, Thailand. 
Received: 14 June 2018 Accepted: 25 December 2018

\section{Published online: 10 January 2019}

\section{References}

1. Chisti Y. Biodiesel from microalgae beats bioethanol. Trends Biotechnol. 2008;26(3):126-31.

2. Beer LL, Boyd ES, Peters JW, Posewitz MC. Engineering algae for biohydrogen and biofuel production. Curr Opin Biotechnol. 2009;20(3): 264-71.

3. Jones CS, Mayfield SP. Algae biofuels: versatility for the future of bioenergy. Curr Opin Biotechnol. 2012;23(3):346-51.

4. Singh A, Olsen SI. A critical review of biochemical conversion, sustainability and life cycle assessment of algal biofuels. Appl Energy. 2011:88(10):3548-55.

5. Wijffels RH, Barbosa MJ. An outlook on microalgal biofuels. Science. 2010; 329(5993):796-9

6. Radakovits R, Jinkerson RE, Darzins A, Posewitz MC. Genetic engineering of algae for enhanced biofuel production. Eukaryot Cell. 2010;9(4):486-501.

7. Georgianna DR, Mayfield SP. Exploiting diversity and synthetic biology for the production of algal biofuels. Nature. 2012;488(7411):329.

8. Potvin G, Zhang Z. Strategies for high-level recombinant protein expression in transgenic microalgae: a review. Biotechnol Adv. 2010;28(6):910-8.

9. Mini P, Demurtas OC, Valentini S, Pallara P, Aprea G, Ferrante P, Giuliano G. Agrobacterium-mediated and electroporation-mediated transformation of Chlamydomonas reinhardtii: a comparative study. BMC Biotechnol. 2018; 18(1):11.

10. Zhang R, Patena W, Armbruster U, Gang SS, Blum SR, Jonikas MC. Highthroughput genotyping of green algal mutants reveals random distribution of mutagenic insertion sites and endonucleolytic cleavage of transforming DNA. Plant Cell. 2014;26(4):1398-409.

11. Radakovits R, Jinkerson RE, Fuerstenberg SI, Tae H, Settlage RE, Boore JL, Posewitz MC. Draft genome sequence and genetic transformation of the oleaginous alga Nannochloropis gaditana. Nat Commun. 2012;3:686.

12. Cerutti H, Johnson AM, Gillham NW, Boynton JE. Epigenetic silencing of a foreign gene in nuclear transformants of Chlamydomonas. Plant Cell. 1997; 9(6):925-45

13. Kurniasih SD, Yamasaki T, Kong F, Okada S, Widyaningrum D, Ohama T. UVmediated Chlamydomonas mutants with enhanced nuclear transgene expression by disruption of DNA methylation-dependent and independent silencing systems. Plant Mol Biol. 2016;92(6):629-41.

14. Sodeinde OA, Kindle KL. Homologous recombination in the nuclear genome of Chlamydomonas reinhardtii. Proc Natl Acad Sci U S A. 1993; 90(19):9199-203.

15. Gumpel NJ, Rochaix JD, Purton S. Studies on homologous recombination in the green alga Chlamydomonas reinhardtii. Curr Genet. 1994;26(5):438-42.

16. Jiang W, Brueggeman AJ, Horken KM, Plucinak TM, Weeks DP. Successful transient expression of Cas 9 and single guide RNA genes in Chlamydomonas reinhardtii. Eukaryot Cell. 2014:13(11):1465-9.

17. Kilian O, Benemann CS, Niyogi KK, Vick B. High-efficiency homologous recombination in the oil-producing alga Nannochloropsis sp. Proc Natl Acad Sci U S A. 2011;108(52):21265-9.

18. Wang $Q$, Lu Y, Xin Y, Wei L, Huang $S$, Xu J. Genome editing of model oleaginous microalgae Nannochloropsis spp. by CRISPR/Cas9. Plant J. 2016; 88(6):1071-81.

19. Fuhrmann M, Oertel W, Hegemann P. A synthetic gene coding for the green fluorescent protein (GFP) is a versatile reporter in Chlamydomonas reinhardtii. Plant J. 1999;19(3):353-61.

20. Schroda M, Blöcker D, Beck CF. The HSP70A promoter as a tool for the improved expression of transgenes in Chlamydomonas. Plant J. 2000; 21(2):121-31.

21. Neupert J, Karcher D, Bock R. Generation of Chlamydomonas strains that efficiently express nuclear transgenes. Plant J. 2009;57(6):1140-50.

22. Lauersen KJ, Kruse O, Mussgnug JH. Targeted expression of nuclear transgenes in Chlamydomonas reinhardtii with a versatile, modular vector toolkit. Appl Microbiol Biotechnol. 2015;99(8):3491-503.

23. Rasala BA, Lee PA, Shen Z, Briggs SP, Mendez M, Mayfield SP. Robust expression and secretion of Xylanase 1 in Chlamydomonas reinhardtii by fusion to a selection gene and processing with the FMDV 2A peptide. PLoS One. 2012;7(8):e43349.

24. Zorin B, Grundman O, Khozin-Goldberg I, Leu S, Shapira M, Kaye Y, Tourasse $\mathrm{N}$, Vallon O, Boussiba S. Development of a nuclear transformation system for oleaginous green alga Lobosphaera (Parietochloris) incisa and genetic complementation of a mutant strain, deficient in arachidonic acid biosynthesis. PLoS One. 2014;9(8):e105223.

25. Guo SL, Zhao XQ, Tang Y, Wan C, Alam MA, Ho SH, Bai FW, Chang JS. Establishment of an efficient genetic transformation system in Scenedesmus obliquus. J Biotechnol. 2013;163(1):61-8.

26. Dautor Y, Úbeda-Mínguez P, Chileh T, García-Maroto F, Alonso DL. Development of genetic transformation methodologies for an industriallypromising microalga: Scenedesmus almeriensis. Trends Biotechnol. 2014; 36(12):2551-8.

27. Úbeda-Mínguez P, Chileh T, Dautor Y, García-Maroto F, Alonso DL. Tools for microalgal biotechnology: development of an optimized transformation method for an industrially promising microalga-Tetraselmis chuii. J Appl Phycol. 2015;27(1):223-32.

28. Chen CY, Kao AL, Tsai ZC, Chow TJ, Chang HY, Zhao XQ, Chen PT, Su HY, Chang JS. Expression of type 2 diacylglycerol acyltransferase gene DGTT1 from Chlamydomonas reinhardtii enhances lipid production in Scenedesmus obliquus. Biotechnol J. 2016;11(3):336-44.

29. Simon DP, Anila N, Gayathri K, Sarada R. Heterologous expression of $\beta$ carotene hydroxylase in Dunaliella salina by agrobacterium-mediated genetic transformation. Algal Res. 2016:18:257-65.

30. Kumar SV, Misquitta RW, Reddy VS, Rao BJ, Rajam MV. Genetic transformation of the green alga-Chlamydomonas reinhardtii by Agrobacterium tumefaciens. Plant Sci. 2004;166(3):731-8.

31. Gim GH, Kim JK, Kim HS, Kathiravan MN, Yang H, Jeong SH, Kim SW. Comparison of biomass production and total lipid content of freshwater green microalgae cultivated under various culture conditions. Bioprocess Biosyst Eng. 2014;37(2):99-106.

32. Ryan MD, King AM, Thomas GP. Cleavage of foot-and-mouth disease virus polyprotein is mediated by residues located within a 19 amino acid sequence. J Gen Virol. 1991;72(11):2727-32.

33. Stevens DR, Purton S, Rochaix JD. The bacterial phleomycin resistance gene ble as a dominant selectable marker in Chlamydomonas. Mol Gen Genet. 1996;251(1):23-30.

34. Rasala BA, Barrera DJ, Ng J, Plucinak TM, Rosenberg JN, Weeks DP, Oyler GA, Peterson TC, Haerizadeh F, Mayfield SP. Expanding the spectral palette of fluorescent proteins for the green microalga Chlamydomonas reinhardtii. Plant J. 2013;74(4):545-56.

35. Rasala BA, Chao SS, Pier M, Barrera DJ, Mayfield SP. Enhanced genetic tools for engineering multigene traits into green algae. PLoS One. 2014;9(4):e94028.

36. Kong F, Yamasaki T, Kurniasih SD, Hou L, Li X, Ivanova N, Okada S, Ohama T. Robust expression of heterologous genes by selection marker fusion system in improved Chlamydomonas strains. J Biosci Bioeng. 2015;120(3):239-45.

37. Plucinak TM, Horken KM, Jiang W, Fostvedt J, Nguyen ST, Weeks DP. Improved and versatile viral 2A platforms for dependable and inducible high-level expression of dicistronic nuclear genes in Chlamydomonas reinhardtii. Plant J. 2015:82(4):717-29.

38. McCarthy SS, Kobayashi MC, Niyogi KK. White mutants of Chlamydomonas reinhardtii are defective in phytoene synthase. Genetics. 2004;168(3):1249-57.

39. Rajam MV, Kumar SV. Green alga (Chlamydomonas reinhardtii). In: Wang K, editor. Methods in molecular biology: Agrobacterium protocols, vol. 2. New Jersey: Human Press; 2006. p. 421-33. Part VIII.

40. Pratheesh PT, Vineetha M, Kurup GM. An efficient protocol for the Agrobacterium-mediated genetic transformation of microalga Chlamydomonas reinhardtii. Mol Biotechnol. 2014:56(6):507-15.

41. Kathiresan S, Chandrashekar A, Ravishankar GA, Sarada R. Agrobacteriummediated transformation in the green alga Haematococcus pluvialis (Chlorophyceae, Volvocales). J Phycol. 2009;45(3):642-9.

42. Anila N, Chandrashekar A, Ravishankar GA, Sarada R. Establishment of Agrobacterium tumefaciens-mediated genetic transformation in Dunaliella bardawil. Eur J Phycol. 2011;46(1):36-44.

43. Cheng R, Ma R, Li K, Rong H, Lin X, Wang Z, Yang S, Ma Y. Agrobacterium tumefaciens mediated transformation of marine microalgae Schizochytrium. Microbiol Res. 2012;167(3):179-86.

44. Cha TS, Chen CF, Yee W, Aziz A, Loh SH. Cinnamic acid, coumarin and vanillin: alternative phenolic compounds for efficient Agrobacteriummediated transformation of the unicellular green alga, Nannochloropsis sp. J Microbiol Methods. 2011:84(3):430-4.

45. San Cha T, Yee W, Aziz A. Assessment of factors affecting Agrobacteriummediated genetic transformation of the unicellular green alga, Chlorella vulgaris. World J Microbiol Biotechnol. 2012;28(4):1771-9. 
46. Sanitha M, Radha S, Fatima AA, Devi SG, Ramya M. Agrobacterium-mediated transformation of three freshwater microalgal strains. Pol J Microbiol. 2014; 63:387-92.

47. Kong F, Yamasaki T, Ohama T. Expression levels of domestic cDNA cassettes integrated in the nuclear genomes of various Chlamydomonas reinhardtii strains. J Biosci Bioeng. 2014;117(5):613-6.

48. Babinger P, Kobl I, Mages W, Schmitt R. A link between DNA methylation and epigenetic silencing in transgenic Volvox carteri. Nucleic Acids Res. 2001;29(6):1261-71.

49. Bird A. DNA methylation patterns and epigenetic memory. Genes Dev. 2002:16(1):6-21.

50. Fuks F, Hurd PJ, Wolf D, Nan X, Bird AP, Kouzarides T. The methyl-CpGbinding protein MeCP2 links DNA methylation to histone methylation. J Bio Chem. 2003;278(6):4035-40.

51. Lumbreras V, Stevens DR, Purton S. Efficient foreign gene expression in Chlamydomonas reinhardtii mediated by an endogenous intron. Plant J. 1998;14:441-7.

52. Eichler-Stahlberg A, Weisheit W, Ruecker O, Heitzer M. Strategies to facilitate transgene expression in Chlamydomonas reinhardtii. Planta. 2009:229:873-83.

53. Lauersen KJ, Berger H, Mussgnug JH, Kruse O. Efficient recombinant protein production and secretion from nuclear transgenes in Chlamydomonas reinhardtii. J Biotechnol. 2013;167(2):101-10.

54. Sizova I, Fuhrmann M, Hegemann PA. Streptomyces rimosusa phVIII gene coding for a new type phosphotransferase provides stable antibiotic resistance to Chlamydomonas reinhardtii. Gene. 2001;277(1):221-9.

55. Steinbrenner J, Sandmann G. Transformation of the green alga Haematococcus pluvialis with a phytoene desaturase for accelerated astaxanthin biosynthesis. Appl Environ Microbiol. 2006;72(12):7477-84

56. Liu J, Gerken H, Huang J, Chen F. Engineering of an endogenous phytoene desaturase gene as a dominant selectable marker for Chlamydomonas reinhardtii transformation and enhanced biosynthesis of carotenoids. Process Biochem. 2013:48(5):788-95.

57. Liu J, Sun Z, Gerken H, Huang J, Jiang Y, Chen F. Genetic engineering of the green alga Chlorella zofingiensis: a modified norflurazon-resistant phytoene desaturase gene as a dominant selectable marker. Appl Microbio Biotechnol. 2014;98(11):5069-79.

58. Lin G, Wang Y, Guo L, Ding H, Hu Y, Liang S, Zhang Z, Yang G. Verification of mutagen function of Zeocin in Nannochloropsis oceanica through transcriptome analysis. J Ocean Univ China. 2017;16(3):501-8.

59. Chen S, Songkumarn P, Liu J, Wang GL. A versatile zero background Tvector system for gene cloning and functional genomics. Plant Physiol. 2009:150(3):1111-21.

60. De Rybel B, van den Berg W, Lokerse AS, Liao CY, van Mourik H, Möller B, Llavata-Peris Cl, Weijers D. A versatile set of ligation-independent cloning vectors for functional studies in plants. Plant Physiol. 2011;156(3):1292-9.

61. Fischer N, Rochaix JD. The flanking regions of PsaD drive efficient gene expression in the nucleus of the green alga Chlamydomonas reinhardtii. Mol Gen Genet. 2001;265(5):888-94.

62. Pollock SV, Colombo SL, Prout DL, Godfrey AC, Moroney JV. Rubisco activase is required for optimal photosynthesis in the green alga Chlamydomonas reinhardtii in a low-CO2 atmosphere. Plant Physiol. 2003; 133(4):1854-61.

63. Jeong JY, Yim HS, Ryu JY, Lee HS, Lee JH, Seen DS, Kang SG. One-step sequence-and ligation-independent cloning as a rapid and versatile cloning method for functional genomics studies. Appl Environ Microbiol. 2012; 78(15):5440-3

64. Mishra SK, Suh WI, Faroog W, Moon M, Shrivastav A, Park MS, Yang JW. Rapid quantification of microalgal lipids in aqueous medium by a simple colorimetric method. Bioresour Technol. 2014;155:330-3.

Ready to submit your research? Choose BMC and benefit from:

- fast, convenient online submission

- thorough peer review by experienced researchers in your field

- rapid publication on acceptance

- support for research data, including large and complex data types

- gold Open Access which fosters wider collaboration and increased citations

- maximum visibility for your research: over $100 \mathrm{M}$ website views per year

At $\mathrm{BMC}$, research is always in progress.

Learn more biomedcentral.com/submissions 